\title{
SISTEM HIDROPONIK BERBASIS INTERNET OF THINGS
}

\section{Hydroponic System Based on Internet Of Things}

\author{
Irene Setiawati ${ }^{1}$, Budi Harsono ${ }^{1}$ \\ ${ }^{1}$ Program Studi Teknik Elektro, Universitas Kristen Krida Wacana \\ Jl. Tanjung Duren Raya No.4, Jakarta, Indonesia \\ Email: irene.2014te009@civitas.ukrida.ac.id, budi.harsono@ukrida.ac.id
}

\begin{abstract}
ABSTRAK
Sistem hidroponik berbasis Internet of Things yang dirancang adalah sistem hidroponik yang dilengkapi perangkat untuk memantau suhu, $\mathrm{pH}$ dan ketinggian air melalui media internet. Perangkat keras terdiri dari sensor $\mathrm{pH}$, sensor suhu, sensor ultrasonik, relay dan pompa air yang dipasang pada kit hidroponik. Arduino sebagai mikrokontroler untuk memproses data yang dihubungkan dengan modul Ethernet Shield agar dapat terhubung dengan internet, ThingSpeak sebagai platform untuk menyimpan data dari Arduino, serta Smartphone digunakan untuk menampilkan hasil dan memantau suhu dan $\mathrm{pH}$ air. Dari hasil pengujian, alat ini mampu bekerja secara otomatis berdasarkan hasil pembacaan sensor dan hasilnya dapat dipantau jarak jauh melalui smartphone tanpa adanya batasan jarak selama terhubung dengan jaringan internet. Hasil pengujian memperlihatkan pengiriman data dari Arduino Uno ke Ethernet Shield, ThingSpeak, dan aplikasi ThingView dapat berjalan baik, dengan waktu pembacaan data minimal 22 detik, maksimal 24 detik.
\end{abstract}

Kata kunci: sensor suhu, sensor pH, ThingSpeak, Internet of Things, hidroponik.

\section{ABSTRACT}

The designed Internet of Things (IOT) based hydroponics system utilizes devices to monitor various parameters such as temperature, $\mathrm{pH}$ and water level through internet media. The hardware part consists of $\mathrm{pH}$ sensors, temperature sensors, ultrasonic sensors, relays and water pumps that is installed in hydroponic kits. The Arduino board is used to process data that is connected with an Ethernet Shield module for internet connection. ThingSpeak is functioned as a platform to store data from Arduino, and a smartphone $s$ used to display results and also to monitor temperature and $\mathrm{pH}$ of water. Experiment result shows that the developed devices is able to automatically read the data from sensor and the result can be remotely monitored via a smartphone without distance restrictions when the internet connection is available. The experiment result also shows that the data transferred from Arduino Uno to Ethernet Shield, ThingSpeak, and the ThingView application work well. The time spends to read the data is minimum of 22 seconds and maximum of 24 seconds.

Key words: temperature sensor, pH sensor, ThingSpeak, Internet of Things, hydroponics

\section{PENDAHULUAN}

Hidroponik adalah metode bercocok tanam atau budidaya tanaman tanpa menggunakan tanah, melainkan menggunakan air, nutrisi, dan oksigen (Agus Suryanto, 2017). Kelebihan sistem hidroponik adalah penggunaan lahan, pupuk dan air lebih efisien, kualitas produksi lebih tinggi dan bersih, serta pengendalian hama dan penyakit lebih mudah. Bercocok tanam dengan metode hidroponik diperlukan pemantauan secara rutin dan intensif terhadap suhu dan $\mathrm{pH}$ air. Terdapat beberapa jenis sistem hidroponik,

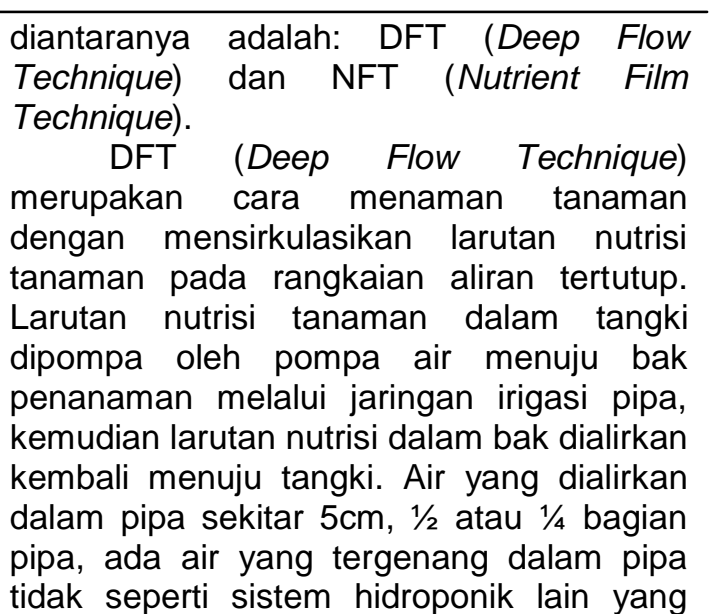


semua nutrisinya selalu mengalir tidak tergenang. Kelebihan DFT terletak pada ketersediaan air nutrisi yang selalu konstan, sehingga bila terjadi pemadaman listrik, tanaman tidak akan kekurangan air karena ada cadangan nutrisi yang tergenang dalam pipa. Kelemahan sistem DFT adalah pada pemakaian nutrisi yang lebih boros dan kemungkinan bisa menjadi sarang nyamuk bila tidak secara rutin dilakukan pengecekan atau pembersihan pipa. Gambar 1(a) menunjukkan skema sistem hidroponik DFT. (O. Untung, 2004).

Pada sistem NFT (Nutrient Film Technique), nutrisi dipompa ke tanaman melalui aliran air yang tipis, sehingga akar tumbuhan bersentuhan dengan lapisan tipis nutrisi yang mengalir. Ketinggian lapisan air bisa diatur satu sampai dua sentimeter. Konstruksi sistem dibuat bertingkat sehingga cairan nutrisi dipompa melalui pipa paling atas kemudian mengalir sampai pipa paling bawah dan langsung ke wadah penampungan cairan pupuk. Akar yang ada pada tanaman akan menyerap lebih banyak oksigen karena hanya ujung akar saja yang bersentuhan dengan larutan nutrisi, hal ini menyebabkan tumbuhan lebih cepat tumbuh dan berkembang. Gambar 1(b) menunjukkan skema sistem hidroponik NFT.

Internet of Things (IoT) adalah kemajuan teknologi yang membantu komunikasi antara satu perangkat dengan perangkat yang lain menggunakan jaringan internet sebagai penghubung (Ibadarrohman, et.al., 2018). IoT memiliki peran dalam pengiriman data jarak jauh melalui komputer yang terkoneksi ke jaringan internet. Melalui internet dapat berbagi data, remote control, dan berbagai hal lainnya. IOT bekerja dengan menerjemahkan bahasa pemrograman yang sudah dimasukkan ke dalam mikrokontroler. Adanya IoT sebagai sistem kontrol pada perangkat memudahkan komunikasi sehingga menjadi lebih cepat dan mudah.

IOT yang menggunakan jaringan internet bersifat multifungsi salah satunya yaitu penggunaan IoT embedded system (sistem tertanam) dengan tujuan dapat menghemat daya. Salah satu pemanfaatan Internet of Things adalah untuk melakukan pemantauan jarak jauh terhadap kondisi tanaman hidroponik. Keunggulan menggunakan Internet of Things diantaranya adalah pengguna dapat memantau kondisi tanaman hidroponik secara realtime. Penggabungan teknologi yang diterapkan pada pertanian dapat menghasilkan produk yang lebih efektif dan berdampak pada pekerjaan manusia yang menjadi lebih mudah dan cepat.

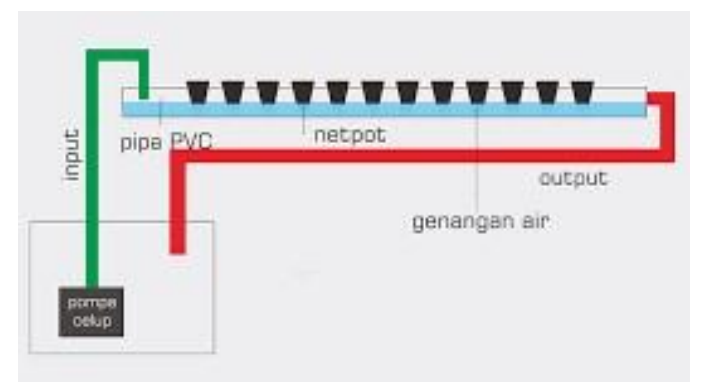

(a)

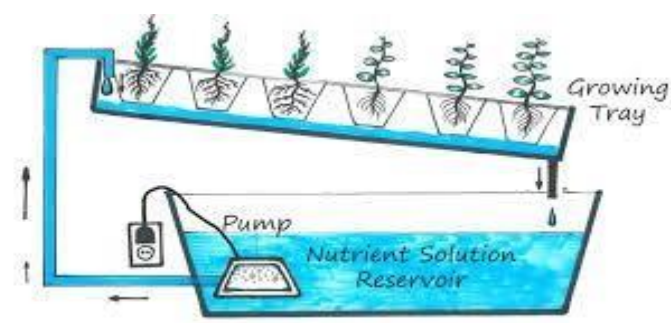

(b)

Gambar 1. Skema sistem hidroponik (a) DFT dan (b) NFT

Beberapa penelitian yang telah dilakukan sebelumnya yaitu Sistem Monitoring Suhu, Kelembaban, dan Pengendali Penyiraman Tanaman Hidroponik menggunakan aplikasi Blynk Android (Wahyu Adi Prayitno et.al., 2017). Pada penelitian ini menggunakan sensor DHT11 yang berfungsi mendeteksi suhu dan kelembaban dan Arduino Mega yang dilengkapi dengan Ethernet Shield sebagai akuisisi dalam pengiriman data menggunakan internet. RTC digunakan untuk memantau waktu secara realtime dan pada penelitian ini menggunakan sistem hidroponik NFT serta aplikasi Android Blynk untuk membantu dalam pemantauan.

Penelitian lainnya yang membahas tentang pemantauan sistem hidroponik dengan Nutrient Film Technique yang berbasis Wireless sensor network pada sayuran (Gafur Hasan Zam Bahari, 2017). Hidroponik NFT terpantau yang dapat dimonitoring serta dapat dikontrol jarak jauh terhadap kondisi air, kondisi nutrisi, dan kondisi pH. Sistem hidroponik NFT terpantau diintegrasikan dengan menggunakan sistem Internet of Things 
yang terkoneksi secara terus-menerus dengan tujuan memperluas fungsi dari konektivitas internet.

Sistem Kontrol dan Monitoring Hidroponik berbasis android (Ibadarrohman, et.al., 2018) menggunakan sistem NFT (Nutrient Film Technique). Hidroponik dipasang mikrokontroler yang terhubung ke internet akan mengirim data mengenai kondisi air ke aplikasi Smartphone android secara realtime. Selain dari itu dikembangkan sistem kontrol manual dan otomatis untuk mengontrol pH air, ketinggian air, dan nutrisi agar sesuai dengan kondisi yang optimal bagi tumbuhan.

Pada penelitian ini dibuat hidroponik berbasis Internet of Things, menggunakan sistem DFT (Deep Flow Technique) yang dapat dipantau dari jarak jauh. Menggunakan ThingSpeak sebagai platform IoT tempat penyimpanan data, dan sebagai perangkat utama yang diprogram untuk terhubung ke internet dan berkomunikasi dengan smartphone. Data-data yang diambil oleh sensor akan diproses oleh Arduino dan pada akhirnya server akan mengirim data pada Smartphone, sehingga pengguna dapat melakukan monitoring terhadap sistem hidroponik.

\section{METODE PENELITIAN}

Sistem hidroponik yang dibuat dalam penelitian ini terdiri dari sensor-sensor, relay, pompa air, modul mikrokontroler Arduino dan Ethernet Shield. Sensorsensor digunakan untuk memantau parameter-parameter dalam sistem hidroponik, seperti $\mathrm{pH}$, suhu dan ketinggian air. Data $\mathrm{pH}$ dan suhu air yang terbaca oleh mikrokontroler akan dikirimkan ke smartphone pengguna melalui jaringan internet, sedangkan data ketinggian air digunakan saat proses penggantian air dalam wadah hidroponik. Ethernet shield digunakan untuk menghubungkan modul mikrokontroler Arduino ke jaringan internet. Blok diagram dari sistem yang dibuat dapat dilihat pada Gambar 2, sedangkan posisi penempatan sensor pada sistem dapat dilihat pada Gambar 3.

Penjelasan masing-masing bagian dari sistem hidroponik yang dibuat adalah sebagai berikut:

a. Sensor pH

Sensor $\mathrm{pH}$ digunakan untuk mengukur $\mathrm{pH}$ air dalam sistem hidroponik. $\mathrm{pH}$ air yang sesuai untuk sistem hidroponik bergantung dari jenis tanaman. Tabel 1 merupakan nilai $\mathrm{pH}$ yang disarankan untuk beberapa jenis tanaman hidroponik. Jenis sensor $\mathrm{pH}$ yang digunakan dalam sistem hidroponik yang dibuat adalah sensor $\mathrm{pH}$ DFRobot E-201-C. Sensor pH ini dapat mengukur nilai $\mathrm{pH}$ 0-14 dengan ketelitian $\pm 0,1 \mathrm{pH}$ pada $25^{\circ} \mathrm{C}$ dan dengan waktu respon kurang dari 1 menit.

b. Sensor suhu

Sensor suhu digunakan untuk mengukur suhu air dalam wadah tanam hidroponik. Suhu air yang baik untuk pertumbuhan tanaman hidroponik adalah $25-27^{\circ} \mathrm{C}$. Suhu air yang terlalu panas atau terlalu dingin akan mempengaruhi tanaman, tanaman akan layu bahkan mati (Triwanto, 2018). Jenis sensor suhu yang digunakan dalam sistem yang dibuat adalah sensor suhu DFRobot DS18B20 yang bersifat kedap air. Sensor suhu ini dapat mengukur dari $-10^{\circ} \mathrm{C}$ hingga $+85^{\circ} \mathrm{C}$ dengan ketelitian $\pm 0,5^{\circ} \mathrm{C}$.

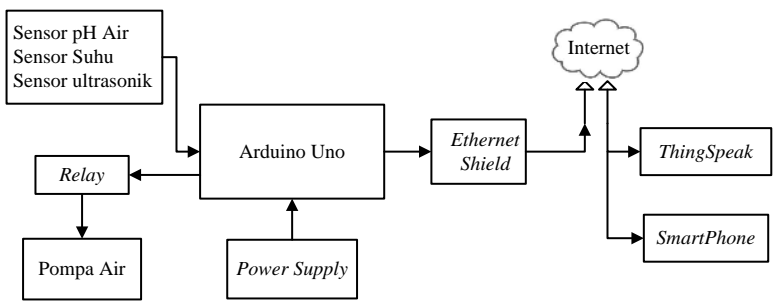

Gambar 2. Blok diagram sistem hidroponik berbasis loT

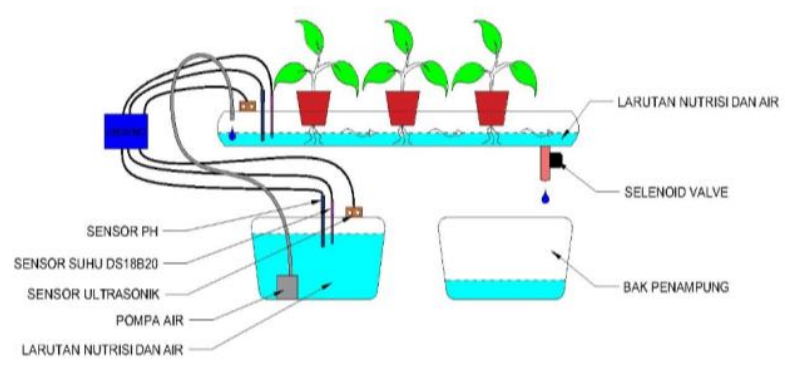

Gambar 3. Posisi penempatan sensor pada sistem hidroponik

\section{c. Sensor ultrasonik}

Sensor ultrasonic digunakan untuk mengukur ketinggian air dalam wadah pada saat proses pengurasan dan pengisian air ke dalam wadah hidroponik. Jenis sensor yang digunakan adalah modul sensor ultrasonik HC-SR04. Untuk dapat mengukur ketinggian air, maka di dalam wadah diletakkan sebuah lempengan plastik yang dapat mengapung mengikuti 
tinggi permukaan air dalam wadah. Ketinggian air dalam wadah dapat dihitung dengan mengurangkan nilai ketinggian modul ultrasonic dari dasar wadah dengan nilai jarak yang terbaca oleh sensor ultrasonik.

\section{d. Pompa air}

Pompa air digunakan untuk memompa air yang telah ditambahkan nutrisi dari bak tampungan ke wadah tanam hidroponik. Pompa air ini dikendalikan melalui sebuah modul relay yang terhubung dengan modul mikrokontroler Arduino.

\section{e. Solenoid valve}

Solenoid valve digunakan sebagai katup untuk membuka dan menutup saluran pembuangan air pada sistem hidroponik yang dibuat. Saat sensor $\mathrm{pH}$ mendeteksi kadar keasaman air sudah tidak sesuai untuk tanaman, maka solenoid valve akan membuka sehingga air akan keluar ke tempat pembuangan. Setelah air terkuras habis, solenoid valve akan menutup dan siap untuk proses pengisian air yang baru.

Tabel 1. Nilai pH beberapa jenis tanaman hidroponik

\begin{tabular}{|c|c|c|}
\hline Nama Sayuran & pH & PPM \\
\hline Bayam & $6.0-7.0$ & $126-161$ \\
\hline Bawang Pre & $6.5-7.0$ & $98-126$ \\
\hline Kubis & $6.5-7.0$ & $175-210$ \\
\hline Selada & $6.0-7.0$ & $56-168$ \\
\hline KembangKol & $6.0-7.0$ & $105-140$ \\
\hline Asparagus & $6.0-6.8$ & $98-120$ \\
\hline Brokoli & $6.0-6.8$ & $196-245$ \\
\hline Kangkung & $5.5-6.5$ & $105-140$ \\
\hline Seledri & 6.5 & $126-168$ \\
\hline
\end{tabular}

f. Modul mikrokontroler Arduino

Modul mikrokontroler Arduino digunakan untuk membaca data dari sensor $\mathrm{pH}$ dan sensor suhu serta mengirimkannya melalui Ethernet shield ke account ThingSpeak. Data sensor pH juga akan diperiksa untuk mengetahui tingkat keasaman air dalam wadah tanam. Jika tingkat keasaman air tidak sesuai untuk tanaman, maka modul Arduino juga akan mengendalikan solenoid valve dan pompa untuk proses pembuangan dan pengisian air.

\section{g. Ethernet shield}

Ethernet shield digunakan untuk menghubungkan modul Arduino ke jaringan internet, sehingga dapat mengirimkan data ke account ThingSpeak yang dapat diakses melalui smartphone pengguna.

Rangkaian lengkap dari sistem hidroponik yang dibuat dapat dilihat pada Gambar 4.

\section{HASIL DAN PEMBAHASAN}

Setelah keseluruhan sistem hidroponik berbasis IoT selesai dibuat, maka perlu dilakukan pengujian untuk mengetahui kinerja dari sistem hidroponik yang telah dibuat. Pegujian yang dilakukan terdiri dari pengujian terhadap sensor $\mathrm{pH}$ dan sensor suhu, modul relay, pompa air dan solenoid valve, serta pengujian pengiriman data dari alat ke aplikasi ThingSpeak dan pengiriman data dari ThingSpeak ke smartphone.

Pengujian sensor $\mathrm{pH}$ dan sensor suhu dilakukan dengan cara membandingkan hasil pengukuran sensor DFRobot E-201-C dan DS18B20 dengan hasil pengukuran yang dilakukan dengan $\mathrm{pH}$ meter digital dan termometer analog. Hasil pengujian sensor $\mathrm{pH}$ dan sensor suhu diberikan pada Tabel 2 dan Tabel 3.

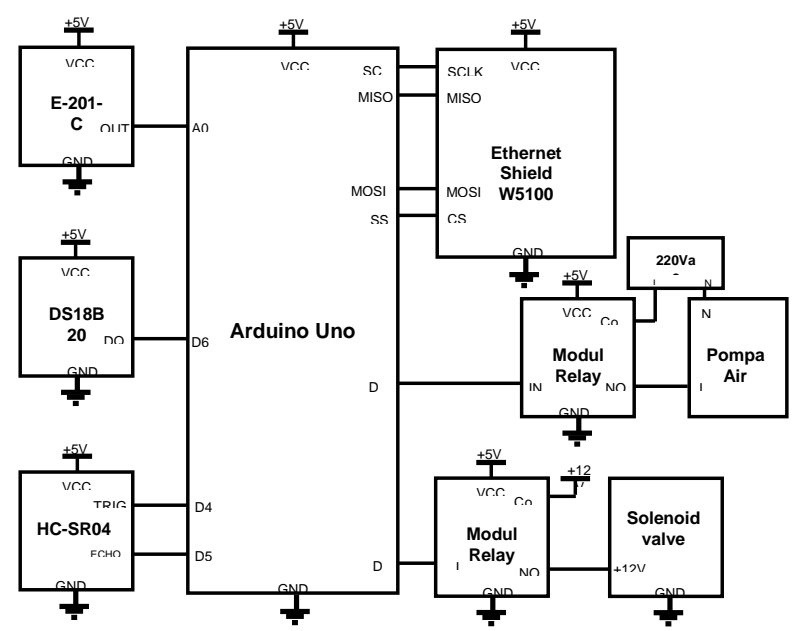

Gambar 4. Rangkaian lengkap sistem hidroponik

Dari hasil pengujian sensor $\mathrm{pH}$ dan sensor suhu diperoleh bahwa nilai pengukuran dari sensor $\mathrm{pH}$ DFRobot $\mathrm{E}$ 201-C dan sensor suhu DS18B20 tidak jauh berbeda dengan hasil pengukuran menggunakan $\mathrm{pH}$ meter digital dan termometer analog, yaitu dengan selisih rata-rata $0,7 \%$ untuk pengukuran dengan sensor $\mathrm{pH}$ dan $1,7 \%$ untuk pengukuran menggunakan sensor suhu. 
Tabel 2. Hasil pengujian sensor $\mathrm{pH} \mathrm{E-201-C}$

\begin{tabular}{|c|c|c|c|}
\hline Pengujian & $\begin{array}{c}\text { Sensor pH } \\
\text { DFRobot E- } \\
\text { 201-C }\end{array}$ & $\begin{array}{c}\text { pH meter } \\
\text { digital }\end{array}$ & $\begin{array}{c}\text { Selisih } \\
(\%)\end{array}$ \\
\hline 1 & 7.1222 & 7.1 & 0.3 \\
\hline 2 & 7.1765 & 7.1 & 1.1 \\
\hline 3 & 7.1493 & 7.1 & 0.7 \\
\hline
\end{tabular}

Tabel 3. Hasil pengujian sensor suhu DS18B20

\begin{tabular}{|c|c|c|c|}
\hline Pengujian & $\begin{array}{c}\text { Sensor Suhu } \\
\text { DFRobot } \\
\text { DS18B20 }\left({ }^{\circ} \mathrm{C}\right)\end{array}$ & $\begin{array}{c}\text { Termometer } \\
\text { Anolog }\left({ }^{\circ} \mathrm{C}\right)\end{array}$ & $\begin{array}{c}\text { Selisih } \\
(\%)\end{array}$ \\
\hline 1 & 28.62 & 28 & 2.2 \\
\hline 2 & 27.56 & 27 & 2.1 \\
\hline 3 & 27.25 & 27 & 0.9 \\
\hline
\end{tabular}

Tahap berikutnya adalah pengujian modul relay, pompa air dan solenoid valve. Pengujian modul relay, pompa air dan solenoid valve dilakukan dengan melihat kinerja pompa air dan solenoid valve saat wadah tanam hidroponik diberikan cairan dengan $\mathrm{pH}$ yang berbeda-beda. Hasil pengujian modul relay, pompa air dan solenoid valve dapat dilihat pada Tabel 4 .

Dari hasil pengujian modul relay, pompa air dan solenoid valve, terlihat bahwa solenoid valve akan bekerja jika $\mathrm{pH}$ air dalam wadah tanam hidroponik bernilai di bawah 6 atau di atas 7. Solenoid valve akan berhenti bekerja jika tinggi permukaan air dalam wadah telah terkuras hingga kurang dari $3 \mathrm{~cm}$ dan pompa air akan bekerja untuk mengisi wadah tanam dengan air dari bak penampungan hingga tinggi air dalam wadah mencapai $8 \mathrm{~cm}$.

Tahap terakhir adalah pengujian pengiriman data dari alat ke aplikasi ThingSpeak dan pengiriman data dari ThingSpeak ke smartphone. Hasil pengujian pengiriman data dari alat ke aplikasi ThingSpeak dan smartphone dapat dilihat pada Tabel 5, sedangkan tampilan data pada ThingSpeak dan smartphone dapat dilihat pada Gambar 5 dan Gambar 6 secara berurutan.
Tabel 4. Hasil pengujian modul relay, pompa air dan solenoid valve

\begin{tabular}{|c|c|c|c|}
\hline $\begin{array}{c}\text { Hasil } \\
\text { Pembacaan } \\
\text { Sensor pH }\end{array}$ & $\begin{array}{c}\text { Hasil } \\
\text { Pembacan } \\
\text { Sensor } \\
\text { Ultrasonik }\end{array}$ & $\begin{array}{c}\text { Relay 1 } \\
\text { dan } \\
\text { Pompa }\end{array}$ & $\begin{array}{c}\text { Relay 2 } \\
\text { dan } \\
\text { Solenoid } \\
\text { valve }\end{array}$ \\
\hline $\begin{array}{c}\mathrm{X}<6 \text { atau } \mathrm{X}> \\
7\end{array}$ & $\geq 3 \mathrm{~cm}$ & OFF & ON \\
\hline $\begin{array}{c}\mathrm{X}<6 \text { atau } \mathrm{X}> \\
7\end{array}$ & $<3 \mathrm{~cm}$ & OFF & OFF \\
\hline $6 \leq \mathrm{X} \leq 7$ & $\leq 3 \mathrm{~cm}$ & ON & OFF \\
\hline $6 \leq \mathrm{X} \leq 7$ & $\geq 8 \mathrm{~cm}$ & OFF & OFF \\
\hline
\end{tabular}

Tabel 5. Hasil pengujian modul pengiriman data

\begin{tabular}{|c|c|c|c|c|}
\hline $\begin{array}{c}\text { Pengujian } \\
\text { ke }\end{array}$ & $\begin{array}{c}\text { Suhu } \\
\left({ }^{\circ} \mathbf{C}\right)\end{array}$ & $\mathbf{p H}$ & $\begin{array}{c}\text { Waktu } \\
\text { terima data }\end{array}$ & $\begin{array}{c}\text { Durasi } \\
\text { (detik) }\end{array}$ \\
\hline 1 & 27.1 & 7.4 & $19: 17: 18$ & - \\
\hline 2 & 27.1 & 7.0 & $19: 17: 41$ & 23 \\
\hline 3 & 27.1 & 7.0 & $19: 18: 03$ & 22 \\
\hline 4 & 27.1 & 7.3 & $19: 18: 26$ & 23 \\
\hline 5 & 27.2 & 7.3 & $19: 18: 48$ & 22 \\
\hline 6 & 27.1 & 7.1 & $19: 19: 12$ & 24 \\
\hline 7 & 27.2 & 7.1 & $19: 19: 34$ & 22 \\
\hline 8 & 27.1 & 7.3 & $19: 19: 57$ & 23 \\
\hline 9 & 27.1 & 7.3 & $19: 20: 19$ & 22 \\
\hline 10 & 27.1 & 7.0 & $19: 20: 41$ & 22 \\
\hline
\end{tabular}

\section{$\square$ ThingSpeak- Channels - Apps - Community}

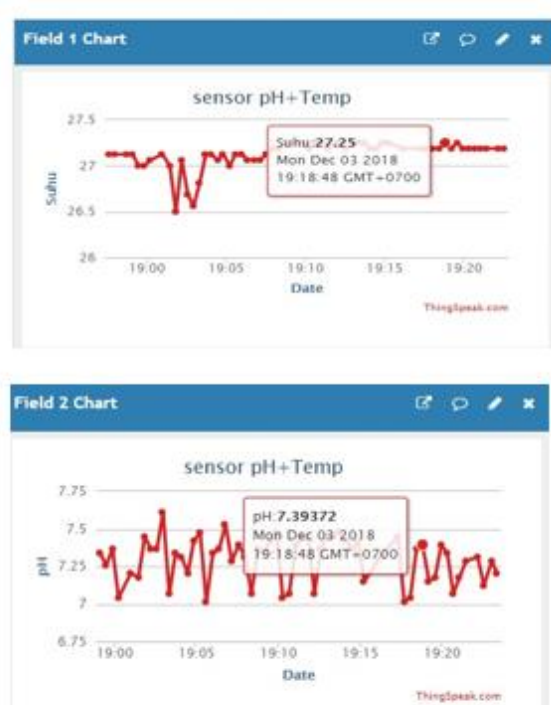

Gambar 5. Tampilan data pada ThingSpeak 


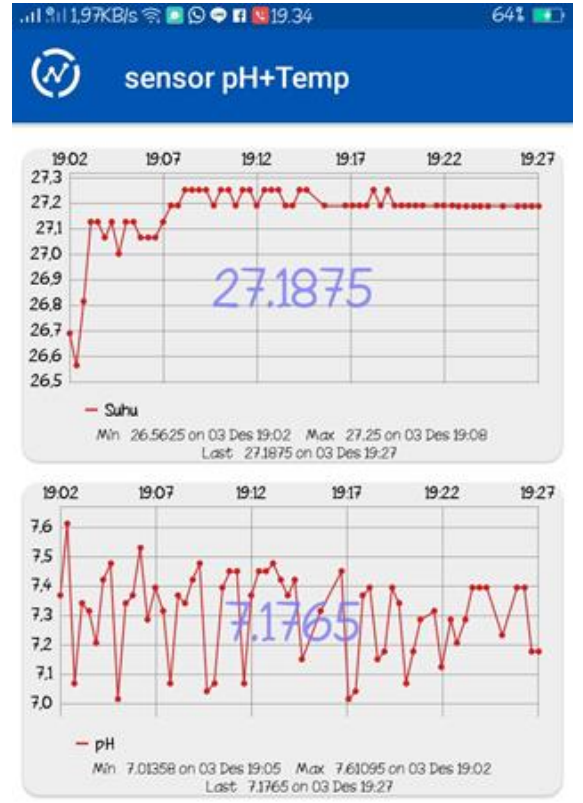

Gambar 6. Tampilan data pada smartphone

Dari hasil pengujian pengiriman data yang dilakukan, terlihat bahwa data-data dari sensor telah berhasil dikirim ke aplikasi ThingSpeak dan smartphone pengguna. Durasi waktu pengiriman data berkisar dari 22 detik hingga 24 detik.

\section{KESIMPULAN}

Dari hasil pengujian sistem hidroponik berbasis loT yang telah dibuat, dapat disimpulkan bahwa:

Sensor pH DFRobot E-201-C dan sensor suhu DS18B20 yang digunakan dalam sistem hidroponik dapat memberikan hasil pembacaan $\mathrm{pH}$ dan suhu dengan selisih yang masih dapat diterima, yaitu 0,7\% untuk pengukuran sensor $\mathrm{pH}$ dan 1,7\% untuk pengukuran sensor suhu. Demikian juga modul relay, pompa air dan solenoid valve dalam sistem hidroponik juga bekerja sesuai dengan perancangan. Relay 2 dan solenoid valve akan bekerja jika $\mathrm{pH}$ air dalam wadah tanam hidroponik bernilai di bawah 6 atau di atas 7. Solenoid valve akan berhenti bekerja jika tinggi permukaan air dalam wadah telah terkuras hingga kurang dari $3 \mathrm{~cm}$ dan pompa air akan bekerja untuk mengisi wadah tanam dengan air dari bak penampungan hingga tinggi air dalam wadah mencapai $8 \mathrm{~cm}$.

Komunikasi alat dengan aplikasi ThingSpeak dapat berjalan dengan baik dengan rata-rata durasi pengiriman data adalah 22-24 detik.
Sistem hidroponik dapat dimonitor dengan Smartphone pengguna untuk dapat menampilkan data suhu dan nilai $\mathrm{pH}$.

\section{REFERENSI}

[1] A. Suryanto, B. Irawan, C. Setianingsih, "Pengembangan Sistem Otomatisasi Pengendalian Nutrisi pada Hidroponik Berbasis Android," e-Proceeding of Engineering, vol. 4, No. 2, pp. 2213-2219, Agustus 2017.

[2] G. H. Z. Bahari, "Internet of Things untuk Pemantauan dan Pengendalian pada Sistem Hidroponik Nutrient Film Technique Sayuran berbasis Wireless Sensor Network," Undergraduate thesis, Institut Teknologi Sepuluh Nopember, 2017.

[3] Ibadarrohman, N. S. Salahuddin, A. Kowanda, "Sistem Kontrol dan Monitoring Hidroponik berbasis Android," Konferensi Nasional Sistem Informasi 2018 STMIK Atma Luhur Pangkalpinang, pp. 177-182, 89 Maret 2018.

[4] O. W. Purbo, "Internet-TCP/IP: Konsep \& Implementasi," Penerbit Andi, 2018.

[5] A. Kadir, "Arduino \& Sensor, Tuntunan Praktis Mempelajari Penggunaan Sensor Untuk Aneka Proyek Elektronika Berbasis Arduino," Penerbit Andi, 2018.

[6] L. R. Valentino, "Simulasi Aplikasi Monitoring Ketinggian Level Air Menggunakan Sensor Ultrasonik HCSR04," Artikel IImiah, Universitas Kristen Satya Wacana Salatiga, Agustus 2012.

[7] I. P. G. Budisanjaya, I. W. Tika, Sumiyati, "Otomatisasi Irigasi pada Budidaya Strawberry Secara Hidroponik di dalam Green House Berbasis Mikrokontroler ATMEGA16," Laporan Akhir Penelitian Hibah Unggulan Program Studi, Universitas Udayana, Nopember 2015.

[8] M. Shalahuddin, A. S. Rosa, "Rekayasa Perangkat Lunak," Penerbit Informatika, 2010.

[9] T. E. Tallei, I. F. M. Rumengan, A. A. Adam," HIDROPONIK untuk Pemula," Penerbit LPPM UNSRAT, 2017.

[10] Triwanto, "Step by Step Merangkai Sendiri Instalasi Hidroponik di Halaman Rumah," Penerbit Cakrawala, 2018.

[11] O. Untung, "Hidroponik Sayuran Sistem NFT (Nutrient Film Technique)," Penerbit Penebar Swadaya Jakarta, 2004.

[12] W. A. Prayitno, A. Muttaqin, dan D. Syaugy, "Sistem Monitoring Suhu, Kelembaban, dan Pengendali Penyiraman Tanaman Hidroponik menggunakan Blynk Android," Jurnal Pengembangan Teknologi Informasi dan IImu Komputer, Vol. 1, No. 4, pp. 292297, April 2017.

[13] M. Wiryanto "Buku Saku Big Data," Penerbit Kementrian Komunikasi dan Informatika, 2015. 